\title{
Biofouling Control in Cooling Water
}

\author{
T. Reg Bott \\ School of Chemical Engineering, University of Birmingham, Birmingham B15 2TT, UK \\ Correspondence should be addressed to T. Reg Bott, t.r.bott@bham.ac.uk
}

Received 25 December 2008; Accepted 17 February 2009

Recommended by Eugénio C. Ferreira

\begin{abstract}
An important aspect of environmental engineering is the control of greenhouse gas emissions. Fossil fuel-fired power stations, for instance, represent a substantial contribution to this problem. Unless suitable steps are taken the accumulation of microbial deposits (biofouling) on the cooling water side of the steam condensers can reduce their efficiency and in consequence, the overall efficiency of power production, with an attendant increase in fuel consumption and hence $\mathrm{CO}_{2}$ production. Biofouling control, therefore, is extremely important and can be exercised by chemical or physical techniques or a combination of both. The paper gives some examples of the effectiveness of different approaches to biofouling control.
\end{abstract}

Copyright (C) 2009 T. Reg Bott. This is an open access article distributed under the Creative Commons Attribution License, which permits unrestricted use, distribution, and reproduction in any medium, provided the original work is properly cited.

\section{Introduction}

The importance of good energy management is becoming far more demanding than in the past. The substantial increase in energy costs and the threat of climate change due to greenhouse gas emissions make it imperative that all steps are taken to reduce energy usage. Of particular importance is the effectiveness of cooling water, specially in the steam condensers of fossil fuel-fired power stations, in maintaining electrical energy output per tonne of fuel at its highest possible level.

Despite efforts to provide an effective design of heat exchanger and careful attention to the maintenance of the design operating conditions, it is likely that fouling on the water side of the heat exchangers will occur unless suitable precautions are taken. The common practice of taking water from natural sources such as rivers and lakes for cooling purposes means that it will contain microorganisms, which will colonise the heat transfer surfaces, to the detriment of cooling efficiency. The problem will be aggravated by the fact that the temperature of the waterside surface in the heat exchanger is usually close to the optimum temperature for maximum microbial growth. In addition water from natural sources will contain nutrients from the breakdown of naturally occurring organic material. Unless this bioactivity is controlled the efficiency of the heat exchanger will be seriously reduced. In fossil fuel-fired power stations this will require additional fuel to be burnt to maintain the required electricity output with an attendant increase in the emission of greenhouse gases. There are basically two methods of controlling this problem, chemical and physical, that might be used separately or in some sort of combination. Three conferences held in Portugal, Melo et al. [1], Melo et al. [2] and International Water Association and Collaborators [3] did much to stimulate interest is these techniques and their effective use. In addition conferences organised byEPI have also covered aspects of the associated technology. The most recent conference was held in Tomar, Portugal in 2007, organised by Müller-Steinhagen et al. [4].

\section{Chemical Control}

In essence chemical control generally involves the use of biocides to kill the microorganisms in the cooling water, or biostats to reduce their activity. For many years the preferred biocide was chlorine because it was relatively cheap and available. However its use is becoming severely restricted on account of its detrimental effects on the quality of the water discharged back to the natural environment from where it was abstracted and its effect on other living creatures, including humans. In contact with organic material in the natural environment chlorine can form chloromethanes that are carcinogenic. An alternative to the discharge of chlorine-contaminated water is to dechlorinate 
before disposal. The techniques for dechlorination are likely to add considerably to the operating costs. As a result efforts are being made to provide alternatives and to be economical in their application. A wide range of chemicals is used as a basis for biocides. They may be classified as oxidising or nonoxidising. Oxidising agents include chlorine and chlorine yielding chemicals, ozone, and hydrogen peroxide. Amongst the nonoxidising compounds are amines, heavy metal compounds, aldehydes, organo-bromine compounds, and isothiazolones.

The so-called "environmentally friendly" biocides are generally those that have a relatively short life after application, breaking down to innocuous products. Simple examples are ozone which reverts to oxygen on decomposition and hydrogen peroxide that breaks down to water. Alternatives to these inorganic chemicals usually involve complex organic compounds that readily breakdown after application. It also has to be appreciated that sometimes these breakdown products are nutrients for microorganisms!.

Clearly the objective is to remove any biofilm as it forms. In order to be economical and effective, the technology of dosing has to be carefully considered. The addition of chemicals to cooling water may be made in three ways.

(a) Continuous. The maintenance of a fixed concentration in the circulating water; the dose depending on the concentration and species of the microorganisms present.

(b) Shock. An intermittent dose of relatively high concentration maybe only once in 24 hours.

(c) Pulse. Involves dosing on a fixed schedule but more frequently than shock dosing maybe once per hour, for example.

The method of dosing will, in general, depend on the season and the quality of the water involved. Careful choice of dosing regime based on trials, preferably in a pilot plant, will help maximise control and minimise cost. It could be beneficial to employ a side-stream test section on the cooling water system to optimise the dosing regime and to make comparisons between alternative biocides.

Some bacteria can develop a potential tolerance to an applied biocide, particularly biocides that affect cell membranes. A change in the dosing regime or a change in the biocide may be effective in overcoming this drawback. Biocides that actually destroy the cell structure are more likely to be the most effective.

In pilot plant studies [5] using Pseudomonas fluorescens as the biofllm forming speciesin single tubes, bulk water flow velocities of 0.5 and $1.3 \mathrm{~m} / \mathrm{s}$, and a proprietary biocide, the results suggested that pulse dosing, based on comprehensive preliminary testing, is likely to be the most effective regime. This observation is not surprising since pulse dosing is the closest to continuous biocide application.

It is generally considered that the season of the year could affect the accumulation of biofouling since microbial activity will be greatest in the summer when the temperature of the water will be higher than in the other seasons. Some recent work [6] suggests however that it would not be advantageous to modify according to the season, the dosing pattern of $0.2 \mathrm{mg} / \mathrm{L}$ chlorine on a $550 \mathrm{MW}$ power station using sea water as the cooling medium.

An alternative to the use of environmentally friendly biocides to meet discharge regulations is to have "zero discharge," that is, to reuse the cooling water, with only "make up" water to replace operating losses. It would allow less costly biocides to be used but nevertheless such a procedure may be costly in maintaining an overall acceptable quality of the circulating water.

\section{Physical Control}

In theory at least, it should be possible to control biofouling by passing the water through the exchanger at high velocity to increase the removal forces acting on the biofilm. Although this may be feasible, it is not really practical because of the high energy requirement to overcome the large pressure drop involved. There are a number of other physical techniques that may be applied to cooling water systems to reduce the incidence of biofouling, but it has to be said that many are still in the development stage and it remains to be seen if they are practical and economically attractive.

3.1. Circulation of Sponge Rubber Balls. The use of circulating sponge rubber balls with the cooling water through the tubes of steam condensers has been practiced with success, for many years. The balls, having a diameter slightly larger than the internal diameter of the tubes, wipe away any biofilm that begins to form. Cleaning is a random process, so that the concentration of balls in the system has to be sufficiently high so that every tube receives balls frequently enough to ensure effective cleaning. In addition there has to be a replacement policy since the balls lose their effectiveness after a time due to reduced diameter through wear.

3.2. The Use of Inserts. Inserts in tubes, originally intended to boost heat transfer, by the destruction of the laminar sublayer on the tube surface are also capable of reducing the incidence of biofouling at modest water velocities. Two basic types are available: (i) static inserts such as "Hitran" wire wound inserts that break up the laminar sublayer by creating turbulence and associated removal forces at the heat transfer surface and (ii) inserts such as those developed by total, that oscillate in response to the water flow, thereby removing the developing biofilm by abrasion.

Both types of device will increase the pressure drop and hence the operating costs, although this may be offset to some extent by suitable design. Data [7] on the effect of "Hitran" inserts on the accumulation of biofilm consisting of the slime forming species $P$. fluorescens demonstrate that although there is some scatter in the data, it is evident that the presence of the insert reduces the accumulation of biofilm. In one test, after 700 hours operation, the reduction of biofilm accumulation compared to an equivalent test with no insert present was approximately $33 \%$ with a water flow velocity of $0.86 \mathrm{~m} / \mathrm{s}$ and approximately $64 \%$ with a water velocity of $1.27 \mathrm{~m} / \mathrm{s}$. 
TABle 1: Control of biofilm formation with different ultrasound treatments.

\begin{tabular}{lccc}
\hline $\begin{array}{l}\text { Amplitude of } \\
\text { ultrasound \% }\end{array}$ & $\begin{array}{c}\text { Number of } \\
\text { 30-second } \\
\text { bursts }\end{array}$ & $\begin{array}{c}\text { Frequency of } \\
\text { bursts each day }\end{array}$ & $\begin{array}{c}\text { Reduction of } \\
\text { biofilm growth } \\
\text { compared with } \\
\text { no treatment \% }\end{array}$ \\
\hline 20 & 3 & 1 & 20.0 \\
20 & 3 & 6 & 65.5 \\
20 & 1 & 8 & 40.3 \\
\hline
\end{tabular}

TABLE 2: Mean biofilm thickness over a period of 28 days with different treatments.

\begin{tabular}{lcc}
\hline Week & \multicolumn{2}{c}{ Biofilm thickness for different tubes $\mu \mathrm{m}$} \\
Ozone only & Ozone + ultrasound \\
\hline 2 & $26,18,17,18$ & 9,8 \\
3 & $43,15,24,20$ & 11,12 \\
4 & $111,49,60,51$ & 7,5 \\
\hline
\end{tabular}

3.3. The Use of Ultrasound. Ultrasound has the property of disturbing liquids and the structure of solids. It is employed, for instance, to remove hard mineral deposits from heat exchange surfaces exposed to high temperature combustion gases in boiler installations. It has been demonstrated experimentally [8] that biofilm accumulation (P. fluorescens) on the inside of tubes can be reduced by the modest use of ultrasound of $20 \mathrm{kHz}$. Depending on the amplitude (20 or $40 \%$ ), the length (time), and frequency of groups of bursts of ultrasound, the reduction in biofilm accumulation varied between 20 and $93 \%$. The water flow velocity was $1 \mathrm{~m} / \mathrm{s}$. Some further detail is given in Table 1.

A major drawback in respect of the use of ultrasound for the control of biofouling is the initial cost of the equipment and its inclusion in heat exchanger design.

3.4. Circulation of Polymer Fibres. Some preliminary work [7] on the use of Aramid fibres to control biofouling suggests that the technique could be useful. Again using $P$. fluorescens as the biofouling bacterium, it was shown that a concentration of fibres of $100 \mathrm{ppm}$ with a water velocity of $1.6 \mathrm{~m} / \mathrm{s}$ is adequate for effective control of biofilm formation. It was noteworthy that if fibre addition was stopped, a biofilm soon began to form. Considerably more work on the technology will be required however, before it can be applied effectively to industrial cooling water. A major difficulty that would have to be faced would be the recovery of the fibres prior to the final discharge of the water. Fibre removal might also be necessary before passing the water through a cooling tower in a recirculation system, to avoid potential accumulation and associated blockage problems. Some preliminary work suggests that the fibres do not accelerate the wear on the associated pumps.

\section{Combined Chemical and Physical Control}

It is possible that a combination of chemical and physical techniques of control could be more effective than either solely applied.
4.1. Ozone and Ultrasound. Experimental work using a combination of ozone and ultrasound over a four-week period [9], again using $P$. fluorescens as the biofilm former and a water velocity of $1 \mathrm{~m} / \mathrm{s}$ demonstrated that this was a more effective control than ozone alone. During the first week of a four-week period, no treatment was applied to allow a biofilm to develop. The biofilm thickness at the end of that first week ranged from $45-60 \mu \mathrm{m}$. Table 2 presents some of the data obtained during the subsequent three weeks, demonstrating that the application of the ultrasound $(20 \mathrm{kHz}$ at $20 \%$ amplitude) for three minutes each day made a considerable difference to the retention of biofilm. The ozone concentration in the water during these tests was very low, since water containing an ozone concentration of around $2.2-2.8 \mathrm{mg} / \mathrm{L}$ was pumped into the system to be mixed with the bulk water for only three hours each day. The data contained in Table 2 indicate that the application of ultrasound made a considerable reduction in the accumulated biofilm.

4.2. Propriety Biocide and Inserts. Limited results [10] using Hitran inserts in conjunction with a propriety biocide have demonstrated that whereas a biocide concentration of around $50 \mathrm{mg} / \mathrm{L}$ would normally be required to control biofilm formation, in the presence of inserts, the concentration required could be as low as $10 \mathrm{mg} / \mathrm{L}$. The conditions of these tests were similar to those quoted elsewhere in this paper.

\section{Concluding Remarks}

This brief summary of investigations into the factors that influence biofilm formation and perhaps more importantly the opportunities for control of biofilm growth demonstrate how the application of chemical engineering and associated technologies can help meeting the challenge of climate change and the associated impact on the well-being of humanity.

Conferences such as Chempor do much to spread the word about what is possible through the application of chemical engineering principles. Furthermore the "networking" that is a direct result of conference attendance is extremely valuable in that it facilitates a combined approach to meeting the challenge.

\section{References}

[1] L. F. Melo, T. R. Bott, and C. A. Bernardo, Fouling Science and Technology, Kluwer Academic Publishers, Dordrecht, The Netherlands, 1988.

[2] L. F. Melo, T. R. Bott, M. Fletcher, and B. Capedeville, Biofilms Science and Technology, Kluwer Academic Publishers, Dordrecht, The Netherlands, 1992.

[3] International Water Association and Collaborators, International Specialised Conference on Befouling Monitoring, 2000.

[4] H. Müller-Steinhagen, M. Reza Malayeri, and A. P. Watkinson, Eds., Heat Exchanger Fouling and Cleaning VII, Engineering Conferences International, Tomar, Portugal, July 2007. 
[5] D. M. Grant and T. R. Bott, "Biocide dosing strategies for biofilm control," Heat Transfer Engineering, vol. 26, no. 1, pp. 44-50, 2005.

[6] T. Casanueva Robles, Estudio y Control del Biofouling Marino en Tubes de Latón-aluminio y Titanio. Aplicación al Condensador de una Central Térmica, Ph.D. thesis, University of Cadiz, Cadiz, Spain, 2009.

[7] T. R. Bott, "Potential physical methods for the control of biofouling in water systems," Chemical Engineering Research and Design, vol. 79, no. 4, pp. 484-490, 2001.

[8] T. R. Bott, "Biofouling control with ultrasound," Heat Transfer Engineering, vol. 21, no. 3, pp. 43-49, 2000.

[9] T. R. Bott and L. Tianqing, "Ultrasound enhancement of biocide efficiency," Ultrasonics Sonochemistry, vol. 11, no. 5, pp. 323-326, 2004.

[10] A. M. Wills, T. R. Bott, and I. Gibbard, "The effect of tube inserts on biocide efficacy," in Heat Exchanger Fouling. Fundamental Approaches and Technical Solutions, H. Müller Steinhagen, Ed., Publico, Essen, Germany, 2002. 

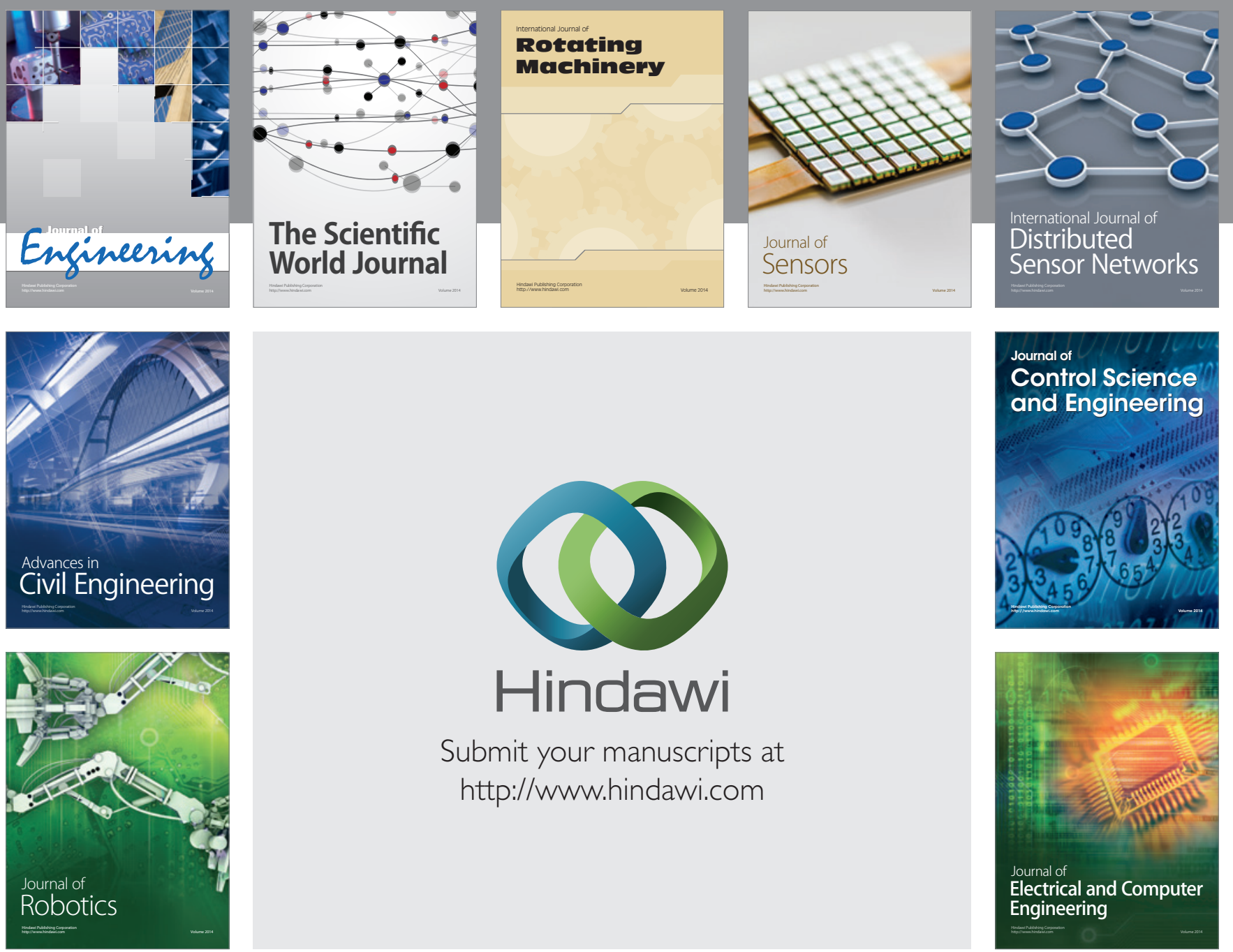

Submit your manuscripts at

http://www.hindawi.com
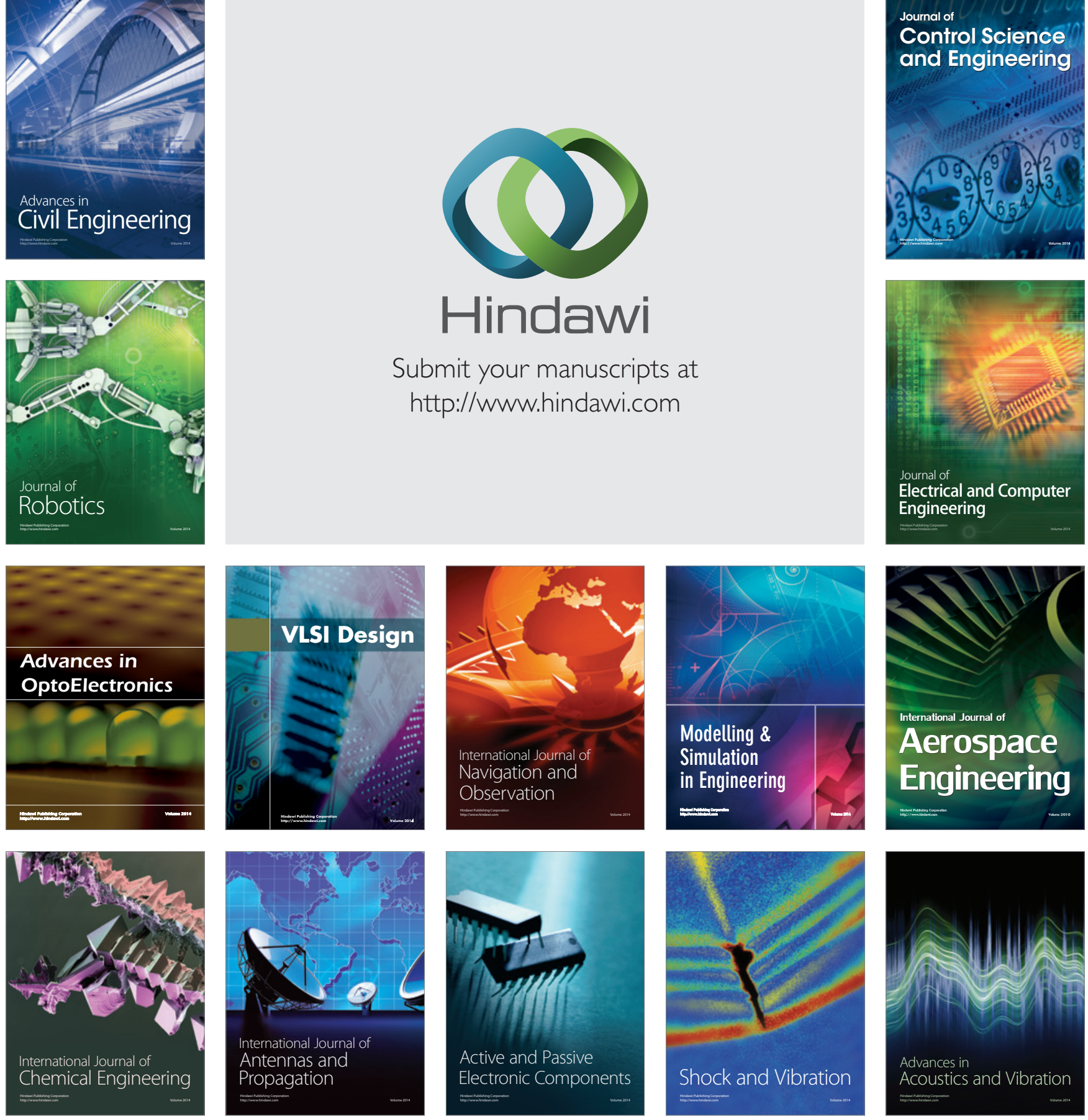